\title{
ENSINO DE BOTÂNICA E CLASSIFICAÇÃO BIOLÓGICA EM UMA ESCOLA FAMÍLIA AGRÍCOLA: DIÁLOGO DE SABERES NO CAMPO
}

\author{
IÊDA TANAN DA SILVA' \\ https://orcid.org/ 0000-0003-2964-5833 \\ ALESSANDRA ALEXANDRE FREIX0" ** \\ https://orcid.org/0000-0003-3566-8302
}

RESUMO: Neste trabalho, buscou-se estabelecer um diálogo de saberes em uma escola do campo, por meio de oficinas que explorassem a diversidade biológica das plantas. Para tanto, realizou-se um levantamento dos conhecimentos prévios de estudantes de uma Escola Família Agrícola sobre as plantas e seus modos de classificação, seguindo uma perspectiva etnobiológica, como meio de promover o diálogo entre o saber tradicional e o científico. $\mathrm{O}$ trabalho foi realizado com turmas do $6^{\circ}$ e $8^{\circ}$ anos do ensino fundamental e teve como suporte teórico-metodológico a pesquisa-ação. Os resultados demonstram que os estudantes têm amplo conhecimento das espécies vegetais que estão em seu cotidiano e utilizam critérios morfológicos e funcionais para categorizá-las. Percebeu-se ainda a significância de oficinas de ciências que abordam aspectos relacionados à classificação biológica, como um instrumento facilitador da aprendizagem de botânica e a valorização dos saberes da comunidade, proporcionando um diálogo entre conhecimento local e científico na escola.

Palavras-chave: Escola Família Agrícola. Etnobotânica. Conhecimento científico. Conhecimento local.

\section{ENSEÑANZA DE LA BOTÁNICA Y CLASIFICACIÓN BIOLÓGICA EN UNA ESCUELA FAMILIAR AGRÍCOLA: DIÁLOGO DE CONOCIMIENTOS EN EL CAMPO}

RESUMEN: En este trabajo, se buscó establecer un diálogo de conocimientos en una escuela rural, a través de talleres que exploraran la diversidad biológica de las plantas. Con este fin, se realizó una encuesta de los conocimientos

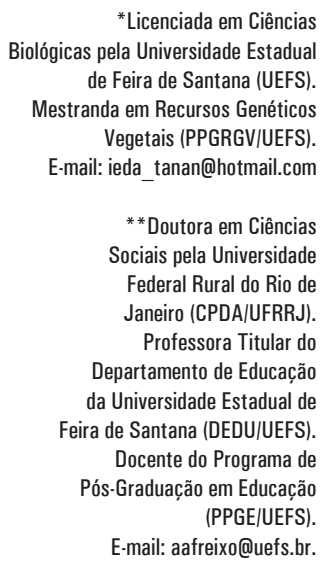

* Licenciada em Ciências Biológicas pela Universidade Estadual de Feira de Santana (UEFS). Mestranda em Recursos Genéticos Vegetais (PPGRGV/UEFS). E-mail: ieda_tanan@hotmail.com

* *Doutora em Ciências Sociais pela Universidade Federal Rural do Rio de Janeiro (CPDA/UFRRJ). Professora Titular do Departamento de Educação da Universidade Estadual de Feira de Santana (DEDU/UEFS). Docente do Programa de Pós-Graduação em Educação (PPGE/UEFS).

E-mail: aafreixo@uefs.br.

I Universidade Estadual de Feira de Santana, Novo Horizonte, BA - Brasil.

II Universidade Estadual de Feira de Santana, Departamento de Educação, Novo Horizonte, BA - Brasil 
previos de los estudiantes sobre las plantas y sus modos de clasificación en una Escuela Familiar Agrícola, siguiendo una perspectiva etnobiológica, como un medio para promover el diálogo entre el conocimiento tradicional y el científico. El trabajo se realizó en las clases de sexto y octavo grado de la educación primaria y tuvo como soporte teórico-metodológico la investigación acción. Los resultados muestran que los estudiantes tienen un amplio conocimiento de las especies de plantas que se encuentran en su vida diaria y utilizan criterios morfológicos y funcionales para clasificarlas. También se notó la importancia de los talleres de ciencias que abordan aspectos relacionados con la clasificación biológica como facilitador del aprendizaje botánico y la valorización del conocimiento de la comunidad, proporcionando un diálogo entre el conocimiento local y científico en la escuela.

Palabras clave: Escuela Familiar Agrícola. Etnobotánica. Conocimiento científico. Conocimiento local.

\section{TEACHING OF BOTANY AND BIOLOGICAL CLASSIFICATION IN AN FAMILY FARM SCHOOL: KNOWLEDGE DIALOGUE ON FIELD}

ABSTRACT: In this paper, we aimed to establish a dialogue of knowledge in a rural school through workshops that explored biological diversity of plants. A survey was carried out aiming to understand the previous knowledge on plants and biological classification modes with students of a Family Farm School. Using Ethnobiology as a theoretical basis, we promote the dialogue between traditional and scientific knowledge. The research was performed with students of $6^{\circ}$ and $8^{\circ}$ grades. The action-research methods were also used as a support in this research. The results show that students have extensive knowledge of different species of plants that are in their daily lives. The research also shows that the students use morphological and functional criteria to categorize plants. In addition, the research has evidenced the significance of science workshops that address aspects related to biological classification as a tool for learning botany and the valorization of community knowledge, providing a dialogue between local and scientific knowledge at school.

Keywords: Family Farm School. Ethnobotany. Scientific knowledge. Local knowledge. 


\section{INTRODUÇÃO}

A botânica compõe uma das maiores áreas de conhecimento da Biologia. Embora as plantas estejam presentes em nosso cotidiano de diversas formas, o ensino sobre elas encontra forte resistência, por apresentar-se de forma descontextualizada, potencializando tanto o desinteresse do professor, como dos alunos (URSI et al. 2018).

$\mathrm{O}$ ensino de botânica, pautado em métodos tradicionais, prevalecendo a memorização de nomes e conceitos, somado ao ensino conteudista nos cursos de Licenciatura, contribuem para o desinteresse e dificuldades nos processos de ensino e aprendizagem sobre as plantas. Assim, trabalhos que valorizem e busquem estratégias para o ensino de botânica são essenciais para um ensino crítico, contextualizado e que forme pessoas conscientes, capazes de compreender a natureza e os processos científicos na sociedade (URSI et al, 2018).

Ainda sobre o ensino de botânica, estudos relacionados a classificação filogenética possibilitam a articulação de conteúdos, ampliando aspectos ecológicos, evolutivos, e morfológicos acerca da biodiversidade vegetal. Para Costa e Waizbort (2013), o ato de classificar está presente em diversas atividades do nosso dia a dia e não apenas na biologia. Classificar é um procedimento humano que está embutido na perspectiva de uma aprendizagem com linguagem natural.

Utilizar relações entre as atividades que costumamos organizar por categorias, como dispensa, guarda-roupas e livros, com o agrupamento realizado pelos taxonomistas torna-se uma ferramenta eficaz acerca da classificação biológica e evolução das plantas, corroborando com Andrade et al. (2014, p. 6393), quando afirmam que "o uso e percepção dos conhecimentos prévios são primordiais na formação dos conceitos, e consequentemente, dos sistemas de categorização e classificação construídos pelos sujeitos."

Este trabalho apresenta o percurso de uma pesquisa desenvolvida em uma Escola Família Agrícola (EFA) inserida no território de identidade do Sisal, a nordeste do estado da Bahia, que visa desenvolver reflexões e alternativas para o ensino de botânica no contexto da educação do campo. A escola segue a Pedagogia da Alternância (PA) como referencial teórico metodológico, em que os alunos revezam uma semana na escola e outra em casa, possibilitando além da articulação dos conhecimentos adquiridos na escola com a comunidade, a formação do sujeito do campo (TEIXEIRA; FREIXO, 2011).

Por adotar a Pedagogia da Alternância (PA), a EFA estabelece uma relação entre o meio em que o aluno está inserido e o ambiente escolar, considerando que a formação no meio rural, para ser completa, depende das relações estabelecidas na escola, na família e na comunidade, como previsto em seu Projeto Político Pedagógico (EFA VALENTE, 2015). Além da articulação dos conhecimentos apreendidos na escola e na comunidade, visa também a valorização do diálogo entre os saberes tradicionais e científico, evidenciando a cultura popular (TEIXEIRA; FREIXO, 2011).

De acordo com Silva (2008), a PA proporciona ao jovem do campo uma educação que entenda as condições de vida no meio rural, seu modo de trabalho e que proporcione uma educação favorecendo as vivências familiares, pois em muitos casos esse jovem participa efetivamente na contribuição do trabalho e renda da família. 
Vergutz e Cavalcante (2014) apontam a PA como um movimento pedagógico que não se caracteriza como um esquema binário nem contextos justapostos ou associados: escola e família, teoria e prática. Ao contrário, aponta para as complementaridades na conexão entre todos os elementos, momentos, contatos, linguagens e experiências possibilitando aos sujeitos envolvidos atuar na sua formação. Ainda segundo os autores, a PA atua no processo de aprendizagem pautado na relação que diagnostica, problematiza, reflete, dialoga, planeja e age através do coletivo.

Os participantes dessa pesquisa estão inseridos em comunidades rurais e detêm uma bagagem de conhecimentos tradicionais e culturais que deve ser considerada. Para Baptista (2010), a demarcação de saberes no ensino de ciências, representa uma segunda cultura para os estudantes de comunidades tradicionais. Assim, o ensino deve ser pautado no diálogo e demarcação de saberes, a fim de promover um espaço formativo que seja significativo para os educandos.

Partindo da relação entre conhecimentos locais, plantas da caatinga e educação do campo, surge a indagação: de que maneira as plantas estão sendo classificadas pelos estudantes da EFA, e quais os limites e potencialidades de uma oficina de ciências que trata do tema classificação biológica como meio de facilitar a compreensão do mesmo e relacioná-los aos conhecimentos locais?

Diante desse questionamento, buscou-se investigar os conhecimentos prévios que os estudantes apresentam sobre as plantas encontradas em seu cotidiano, bem como os sistemas de classificação que utilizam para reconhecêlas. Em adição, buscou-se investigar a importância de uma oficina de ciências como instrumento facilitador no diálogo entre os conhecimentos locais e os conhecimentos científicos sobre o tema classificação biológica.

\section{METODOLOGIA}

Esta pesquisa, de cunho qualitativo, se insere no contexto de um projeto de pesquisa e extensão desenvolvido junto à Escola Família Agrícola em estudo, que visa fortalecer o enraizamento de comunidades no território do sisal tomando como ponto de partida o desenvolvimento de um observatório de juventudes rurais na região sisaleira. Esse observatório tem como principal foco o desenvolvimento participativo de atividades articuladas que promovam a interlocução entre a comunidade escolar (estudantes, professores e profissionais de apoio) e acadêmicos (professores e estudantes universitários), de modo a produzir um acervo documental de pesquisa colaborativa.

Em concordância com este projeto, uma dessas atividades, desenvolvida em conjunto com a equipe pedagógica e coordenada pelas autoras deste artigo, foi a proposição de oficinas de ciências, articuladas ao currículo da escola, de acordo com o método da pesquisa-ação. Tal como propõe Tripp (2005), esta pesquisa passou por uma importante fase de reconhecimento do contexto da escola, da comunidade escolar e das suas práticas pedagógicas. Ainda segundo o autor, a pesquisa-ação consiste em estratégias de caráter interativo que permitem a participação ativa de todos os envolvidos na pesquisa, possibilitando ao pesquisador utilizar sua pesquisa para aprimorar a sua prática. Isto porque ao investigar ele pode refletir sobre a ação, avaliá-la e planejar meios de modificá-la. 
Em sintonia com as proposições de Tripp (2005), nossa pesquisa buscou abarcar tanto aspectos de caráter técnico quanto de caráter prático para a reflexão sobre uma prática pedagógica. Em seu aspecto técnico, tomamos como referência uma atividade já existente - a proposta de utilizar classificações intuitivas, derivada do modelo intuitivo de classificação conforme abordado por Amorim, 1999 (apud FERREIRA et al., 2008) -, para realizar um aprimoramento da prática do ensino de botânica numa escola do campo. No que tange à natureza prática, estabelecemos nossos próprios critérios de investigação com base no grupo com o qual trabalhamos, buscando melhorar nossa prática à medida que implementamos nossa pesquisa-ação.

O campo da pesquisa foi uma Escola Família Agrícola do estado da Bahia, envolvendo uma turma de 17 estudantes do $6^{\circ}$ e outra de 15 estudantes do $8^{\circ}$ ano do ensino fundamental. Esta escola adota a Pedagogia da Alternância como referencial metodológico, que permite ao aluno alternar uma semana na escola e outra em casa, de forma a promover o diálogo e fortalecer a relação entre escola e comunidade. $\mathrm{O}$ período em que o estudante se encontra na escola denomina-se sessão.

A escolha das turmas de $6^{\circ}$ e $8^{\circ}$ anos se deu em virtude da organização do trabalho pedagógico na escola, atendendo a uma demanda formativa dos estudantes, apresentada em algumas das reuniões de planejamento das atividades do projeto, da qual participaram membros da equipe pedagógica da escola e membros da equipe executora do projeto. Assim, visando articular os objetivos do projeto às atividades planejadas na escola, as turmas de $6^{\circ}$ e $8^{\circ}$ anos participaram de oficinas sobre diversidade vegetal, enquanto turmas de $7^{\circ}$ e $9^{\circ}$ anos participaram das oficinas sobre diversidade animal, conforme abordado por Sousa e Freixo (2020). As oficinas foram inicialmente propostas pela equipe executora do projeto de extensão e adequadas em seus objetivos e metodologia em reuniões pedagógicas na escola.

Assim, na primeira sessão, foram contemplados na oficina os estudantes do $6^{\circ}$ ano; numa segunda sessão, as atividades da oficina ocorreram com a turma de $8^{\circ}$ ano. As atividades desenvolvidas com os estudantes aconteceram no espaçotempo do Serão, momento específico presente na proposta curricular da escola e descrito em seu Projeto Político Pedagógico (EFA VALENTE, 2015), no qual os estudantes têm a oportunidade de dialogar com parceiros da escola, visando enriquecer sua formação integral, como parte diversificada do currículo.

A oficina se desenvolveu em três encontros. No primeiro encontro, apresentamos a proposta e os objetivos da oficina, quando os estudantes foram instigados a escolher e falar sobre uma planta que fizesse parte do seu cotidiano. Listamos as plantas escolhidas no quadro, de forma que ficasse visível e não houvesse plantas repetidas. Em seguida, solicitamos que cada estudante escrevesse alguma informação sobre a planta que havia escolhido, como aspectos morfológicos, forma de manejo ou algo que tivessem ouvido de familiares ou em sua comunidade. Durante esse momento, os estudantes foram estimulados a fazer o desenho da espécie que tinham escolhido. Após esse momento, os desenhos e textos foram socializados em uma roda de conversa de modo que todos soubessem sobre as plantas que eles representaram.

No segundo encontro, organizamos os alunos em grupos de até cinco pessoas para que realizassem a atividade de classificação das plantas citadas por eles. Para essa atividade foi necessário material de papelaria (cartolina, tesoura, 
cola e canetas hidrográficas) e imagens obtidas na internet das plantas que foram escolhidas pelos estudantes das duas turmas ( $6^{\circ}$ e $8^{\circ}$ anos). Instruímos os alunos a confeccionarem um cartaz organizando as plantas em conjunto, da forma que achassem mais conveniente usando qualquer critério, como semelhança morfológica, utilidade, hábito, etc. Para elucidar a atividade, utilizamos como exemplo ações domésticas que estão presentes no nosso dia a dia, como arrumar o guarda-roupa, os livros da biblioteca, ou mesmo as compras do mercado.

Após a composição do cartaz, os grupos apresentaram seus critérios e composição dos conjuntos de plantas para a turma, para que todos pudessem visualizar as diferentes possibilidades de grupos formados com os mesmos organismos.

Para sistematizar os dados desse segundo encontro, buscamos informações a respeito das espécies vegetais que foram abordadas pelos estudantes, e classificamos cientificamente as plantas citadas a partir dos nomes populares e dos desenhos apresentados pelos estudantes, recorrendo a sites de classificação filogenética, como o ITIS - Integrated Taxonomic Information System (SHAW, 2004) e o site The Plant List (2013), e utilizamos como ferramenta o site de classificação Phylogenetic Tree Generator (LETUNIC; BORK, 2006), para a confecção de um cladograma abarcando as espécies escolhidas pelas duas turmas.

No terceiro encontro, apresentamos aos estudantes uma introdução sobre classificação biológica, abordando conceitos específicos. Nesse espaço, apresentamos um cartaz similar ao que eles haviam desenvolvido com as imagens das plantas organizadas de acordo com seu grupo monofilético. Iniciamos uma conversa a respeito da importância de ter uma classificação universal dos seres vivos, apresentando alguns critérios utilizados pela comunidade científica e entregamos o livreto que foi produzido a partir das atividades desenvolvidas por eles. Com o livreto em mãos, discutimos as diferenças entre a classificação feita pela ciência e a que eles realizaram, promovendo o diálogo de saberes locais e científicos e articulando com a demarcação de saberes no ensino de ciências, em escolas situadas em comunidades tradicionais (BAPTISTA, 2010). Logo em seguida, realizamos a socialização das atividades desenvolvidas na oficina para toda a comunidade escolar, momento em que os alunos puderam apresentar seus cartazes, bem como avaliar a experiência de participar da oficina e da elaboração do material produzido.

Os materiais coletados por meio de textos e gravações dos encontros foram submetidos a uma análise de conteúdo, conforme proposto por Bardin (2004). Essa análise consistiu de três etapas: 1) pré-análise, momento destinado a organização e preparação dos dados para análise, em que realizamos as transcrições dos áudios, transcrição das falas dos alunos e sistematização dos desenhos; 2) exploração do material, em que envolveu a escolha e delimitação das unidades e categorias de análise, ou seja, demarcamos distintas unidades de sentido presentes nos textos e nas falas dos alunos, possibilitando a criação de categorias de análise a posteriori; 3) tratamento dos resultados: inferência e interpretação dos dados, a partir dos referenciais desenvolvidos neste estudo.

Esta pesquisa seguiu as recomendações éticas da pesquisa envolvendo seres humanos, tendo sido submetida a um Comitê de Ética em Pesquisa, de modo a salvaguardar os direitos dos participantes da pesquisa. Assim, todos os estudantes concordaram em participar mediante assinatura do Termo de Assentimento Livre 
e Esclarecido (TALE), com a anuência de seus responsáveis, mediante assinatura de Termo de Consentimento Livre e Esclarecido (TCLE).

\section{RESULTADOS E DISCUSSÃO}

Buscando responder aos objetivos propostos nessa pesquisa, de investigar os conhecimentos prévios que os estudantes da EFA apresentam sobre as plantas encontradas em seu cotidiano, bem como os sistemas de classificação que utilizam para reconhecê-las, nos apoiamos na perspectiva da etnobiologia, visando discutir a importância da valorização dos conhecimentos tradicionais sob o olhar da etnobotânica, para compreender o processo de diálogo de saberes. Assim, os resultados da pesquisa serão apresentados a seguir de acordo com a ordem apresentada na metodologia.

\subsection{DAS PLANTAS QUE EU CONHEÇO...}

Durante a primeira parte da pesquisa, buscamos saber quais informações os estudantes da EFA traziam sobre as plantas. O Quadro 1 apresenta as espécies que foram escolhidas pela turma do $6^{\circ}$ ano; nele observamos que tal escolha baseia-se nas plantas que estão presentes em seu cotidiano, seja em casa ou na escola, corroborando com resultados obtidos por Lima e Freixo (2012), e na forma com que aquela espécie é utilizada, seja para alimentação humana, no uso medicinal, ou mesmo na ornamentação.

Quadro 1. Relação das plantas escolhidas pelos alunos do $6^{\circ}$ ano da EFA

\begin{tabular}{|l|l|l|}
\hline \multicolumn{1}{|c|}{ Medicinais } & \multicolumn{1}{|c|}{ Alimentação } & \multicolumn{1}{c|}{ Beleza } \\
\hline $\begin{array}{l}\text { Erva-Cidreira } \\
\text { (Melissa officinalis L.) }\end{array}$ & $\begin{array}{l}\text { Acerola } \\
\text { (Malpighia emarginata DC.) }\end{array}$ & $\begin{array}{l}\text { Rosa } \\
\text { (Rosa sp. L.) }\end{array}$ \\
\hline $\begin{array}{l}\text { Aroeira } \\
\text { (Schinus terebinthifolia } \\
\text { Raddi) }\end{array}$ & $\begin{array}{l}\text { Umbuzeiro } \\
\text { (Spondias tuberosa } \\
\text { Arruda) }\end{array}$ & $\begin{array}{l}\text { Barriguda } \\
\text { (Ceiba glaziovii (Kuntze) K. } \\
\text { Schum.) }\end{array}$ \\
\hline $\begin{array}{l}\text { Arruda } \\
\text { (Ruta graveolens L.) }\end{array}$ & $\begin{array}{l}\text { Maçã } \\
\text { (Malus sp.) }\end{array}$ & $\begin{array}{l}\text { Orquídea } \\
\text { (Orchidaceae) }\end{array}$ \\
\hline $\begin{array}{l}\text { Alecrim } \\
\text { (Rosmarinus officinalis L.) }\end{array}$ & $\begin{array}{l}\text { Hortelã miúdo } \\
\text { (Mentha spicata L.) }\end{array}$ & $\begin{array}{l}\text { Cansanção } \\
\text { (Cnidoscolus urens (L.) } \\
\text { Arthur) }\end{array}$ \\
\hline $\begin{array}{l}\text { Capim Santo } \\
\text { (Cymbopogon citratus } \\
\text { (DC.) Stapf.) }\end{array}$ & $\begin{array}{l}\text { Cerejeira } \\
\text { (Prunus cerasus Ledeb.) }\end{array}$ & \\
\hline $\begin{array}{l}\text { Maconha } \\
\text { (Cannabis sativa L.) }\end{array}$ & & \\
\hline $\begin{array}{l}\text { Pau de rato } \\
\text { (Poincianella pyramidalis } \\
\text { (Tul.) L.P.Queiroz) }\end{array}$ & & \\
\hline $\begin{array}{l}\text { Maravilha } \\
\text { (Mirabilis jalapa L.) }\end{array}$ & & \\
\hline
\end{tabular}


As categorias utilizadas na organização dos quadros (para as turmas do $6^{\circ}$ e $8^{\circ}$ anos), foram elaboradas a partir da fala dos estudantes no momento de justificativa para sua escolha, dialogando com Andrade et al. (2014), na perspectiva de que os conhecimentos prévios são essenciais na formação de conceitos, sistemas de categorização e classificação pelos sujeitos.

Das 17 espécies citadas pela turma, 8 foram selecionadas pelo uso medicinal, como apresentado na seguinte fala que justifica a escolha do Pau de rato (Poincianella pyramidalis (Tul.) L. P. Queiroz):

Essa planta serve para fazer chá para dor de barriga. Eu escolhi essa planta porque ela é muito importante para nossa saúde, ficar saudável e muito forte e não ter mais dor de barriga. (Estudante do $6^{\circ}$ ano)

Resultado semelhante foi encontrado por Oliveira e Freixo (2019), em que durante a coleta de plantas para confecção de um herbário digital notaram a preferência dos estudantes pelas plantas medicinais e que os mesmos apresentavam um amplo conhecimento sobre sua utilização. Segundo esses autores, tal conhecimento é adquirido tanto na convivência familiar, quanto nas atividades desenvolvidas na escola.

Lima e Freixo (2012) argumentam que os estudantes da EFA trazem não só o conhecimento das falas de seus pais, avós, como também conhecem visualmente as plantas, pois vivenciam e reconhecem o local em que estão inseridos e estão em contato com essas espécies frequentemente. Essa relação pode ser observada na Figura 1, mostrando o cuidado com a horta ao regar a hortelã. Ainda de acordo com os autores, é nítida a contribuição da família na aquisição desses conhecimentos, bem como as atividades práticas desenvolvidas na escola, por meio das disciplinas Agricultura e Zootecnia, evidenciado na fala do estudante que aponta as diferentes formas de uso para a hortelã (FIGURA 1). 
Figura 1. Hortelã miúdo (Mentha spicata L.)

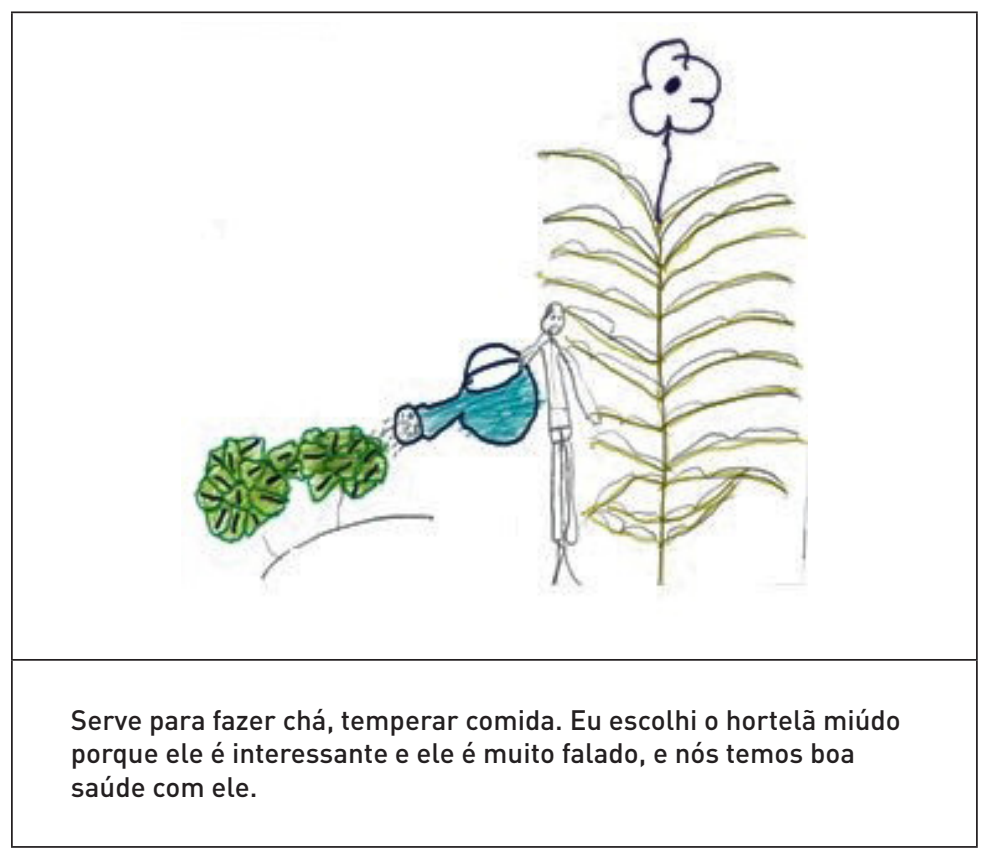

Fonte: Desenho e justificativa elaborados por estudante do $6^{\circ}$ ano da EFA.

Como apresentado no Quadro 2, os estudantes do $8^{\circ}$ ano, escolheram plantas que estão relacionadas ao trabalho, diferente da percepção do $6^{\circ}$ ano. Entre as quinze espécies que foram citadas pelos estudantes, oito são utilizadas exclusivamente na alimentação de animais, três na alimentação humana, uma como ornamental e três como sendo representantes da caatinga. 
Quadro 2. Relação das plantas escolhidas pelos estudantes do $8^{\circ}$ ano da EFA

\begin{tabular}{|l|l|l|l|}
\hline Alimentação Animal & \multicolumn{1}{|c|}{ Caatinga } & \multicolumn{1}{|c|}{ Fruta } & Ornamental/Bonita \\
\hline $\begin{array}{l}\text { Caroá/gravatá } \\
\text { (Neoglaziovia } \\
\text { variegata (Arruda) } \\
\text { Mez) }\end{array}$ & $\begin{array}{l}\text { Cabeça de frade } \\
\text { (Melocactus } \\
\text { zehntneri (Britton \& } \\
\text { Rose) Luetzelb.) }\end{array}$ & $\begin{array}{l}\text { Abacaxi (Ananas } \\
\text { comosus (L.) Merr.) }\end{array}$ & $\begin{array}{l}\text { Cebola brava } \\
\text { (Habranthus } \\
\text { sylvaticus (Mart. ex } \\
\text { Schult. \& Schult.f.) } \\
\text { Herb.) }\end{array}$ \\
\hline $\begin{array}{l}\text { Incó (Capparis yco } \\
\text { Mart.) }\end{array}$ & $\begin{array}{l}\text { Juazeiro (Ziziphus } \\
\text { joazeiro Mart.) }\end{array}$ & $\begin{array}{l}\text { Bananeira (Musa } \\
\text { sp.) }\end{array}$ & \\
\hline $\begin{array}{l}\text { Licurizeiro (Syagrus } \\
\text { coronata (Mart.) } \\
\text { Becc.) }\end{array}$ & $\begin{array}{l}\text { Sisal (Agave } \\
\text { sisalana Perrine) }\end{array}$ & $\begin{array}{l}\text { Cajazeira (Spondias } \\
\text { mombin L.) }\end{array}$ & \\
\hline $\begin{array}{l}\text { Mandacaru (Cereus } \\
\text { jamacaru DC.) }\end{array}$ & & & \\
\hline $\begin{array}{l}\text { Mandioca brava } \\
\text { (Manihot utilissima } \\
\text { Pohl) }\end{array}$ & & & \\
\hline $\begin{array}{l}\text { Palma (Opuntia } \\
\text { chlorotica Engelm. } \\
\text { \& J.M. Bigelow) }\end{array}$ & & & \\
\hline $\begin{array}{l}\text { Quixabeira } \\
\text { (Sideroxylon } \\
\text { obtusifolium (Roem. } \\
\text { \& Schult.) T.D.Penn.) }\end{array}$ & & & \\
\hline $\begin{array}{l}\text { Xique-Xique } \\
\text { (Pilounocereus } \\
\text { Weber ex K. Schum.) } \\
\text { Byles \& G.D. Rowley }\end{array}$ & & & \\
\hline
\end{tabular}

A utilização das espécies na alimentação dos animais é apresentada nas falas com propriedade pelos estudantes, uma vez que já apresentam maior intimidade e responsabilidade com as atividades práticas desenvolvidas na escola e na comunidade. Como apresentado na Figura 2, que ilustra os conhecimentos adquiridos na família, na prática da escola e o reconhecimento de espécies da caatinga. 
Figura 2. Quixabeira (Sideroxylon obtusifolium (Roem. \& Schult.) T.D.Penn.)

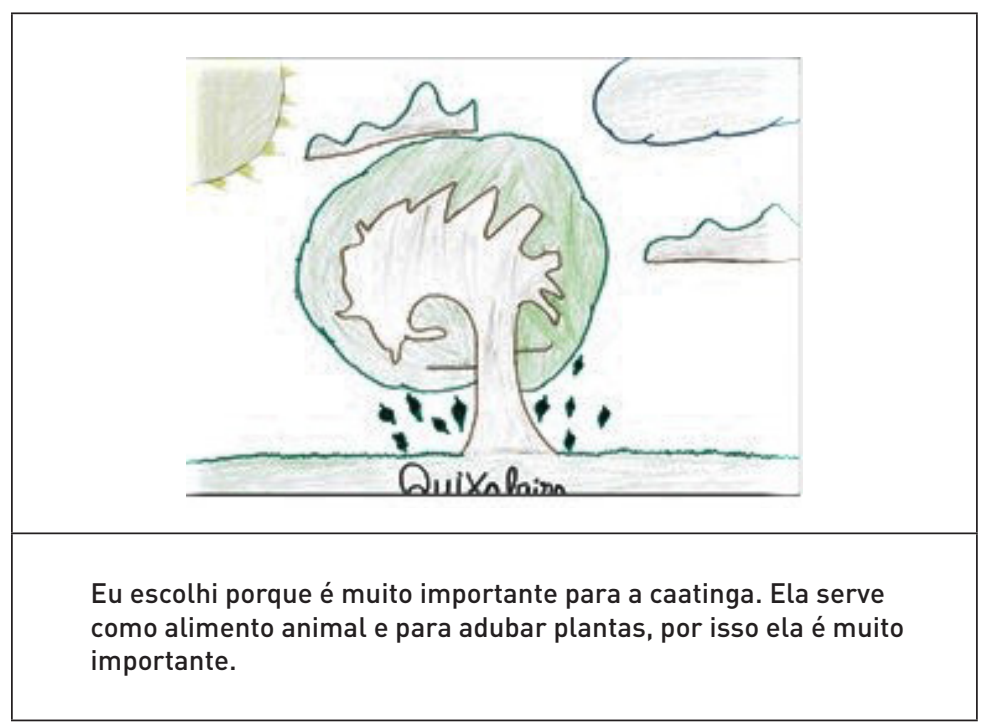

Fonte: Desenho e justificativa elaborados por estudante do $8^{\circ}$ ano da EFA.

A valorização da caatinga e o reconhecimento de suas características, que são trabalhadas na proposta pedagógica da escola, ficam evidenciados nas falas da maioria dos estudantes, com a escolha de espécies que têm importância econômica para a região, nativas da caatinga ou mesmo que servem de alimento para os animais. Teixeira, Silva e Freixo (2018), no mesmo contexto de estudo, buscaram investigar as representações da caatinga feitas por estudantes da EFA, e observaram um forte sentimento de pertencimento, atribuído à proposta pedagógica da escola:

O sentimento de pertencimento à Caatinga e ao semiárido é muito forte entre os estudantes no município de Valente, que representam o bioma como parte de seus elementos identitários, o que provavelmente é reflexo do trabalho pedagógico desta escola do campo (TEIXEIRA; SILVA; FREIXO, 2018, p. 468)

Um estudante também apresentou fala com profunda relação da família na transmissão e diálogo de saberes, corroborando com Lima e Freixo (2012), quando argumentam que os conhecimentos produzidos por comunidades tradicionais sobre o meio ambiente são passados de geração a geração, e ressaltam a importância das plantas da caatinga para aquela comunidade:

Não conheço muito a planta, mas conheço algumas utilidades dessa ilustre planta. Sei que ela serve como alimentação animal, já ouvi meus pais e avós dizendo que o caroá é uma planta de porte médio. E é uma planta da caatinga, o nosso bioma, por isso eu escolhi." (Estudante do $8^{\circ}$ ano)

Na Figura 3 um estudante apresenta uma espécie como sendo representante da caatinga e da região que ele se encontra. Em sua fala nota-se que o mesmo conhece 
espécies nativas da caatinga e reconhece sua importância sociocultural ao afirmar "minha região", demonstrando contraste com outros estudos (BITENCOURT; MARQUES; MOURA, 2014; ARAÚJO; SOBRINHO, 2009) aos quais revelam que os estudantes têm uma visão negativa a respeito desse Bioma.

Figura 3. Juazeiro (Ziziphus joazeiro Mart.)

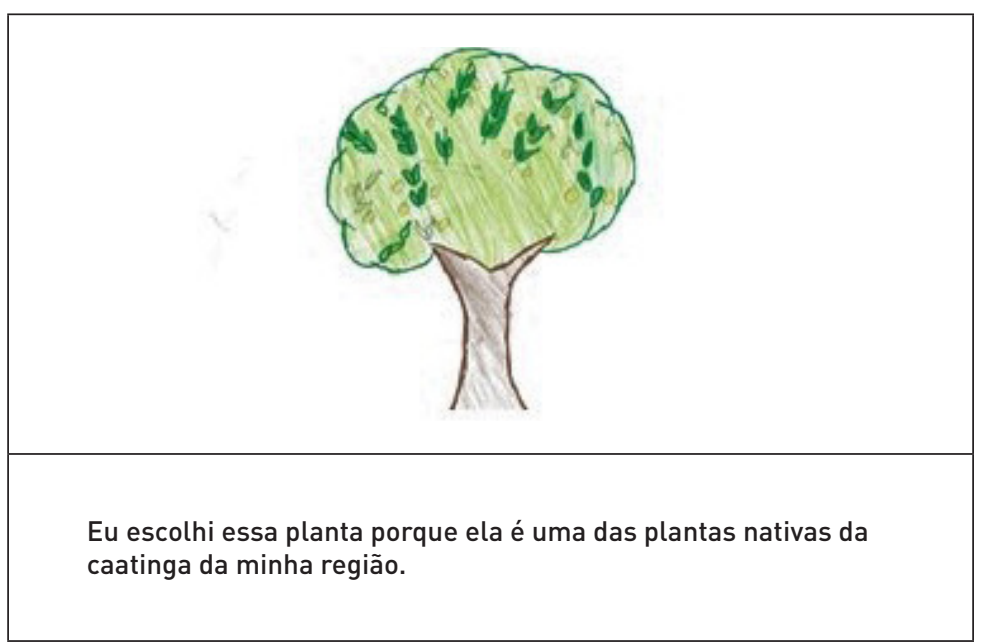

Fonte: Desenho e justificativa elaborados por estudante do $8^{\circ}$ ano da EFA.

Na Figura 4, o mandacaru é apresentado florido, em uma paisagem que prevalece o sol forte e aves pairando no céu. Essa imagem é uma visão oposta de caatinga como ambiente morto e sem vida, visto que o mandacaru está em sua fase reprodutiva. 
Figura 4. Mandacaru (Cereus jamacaru DC.)

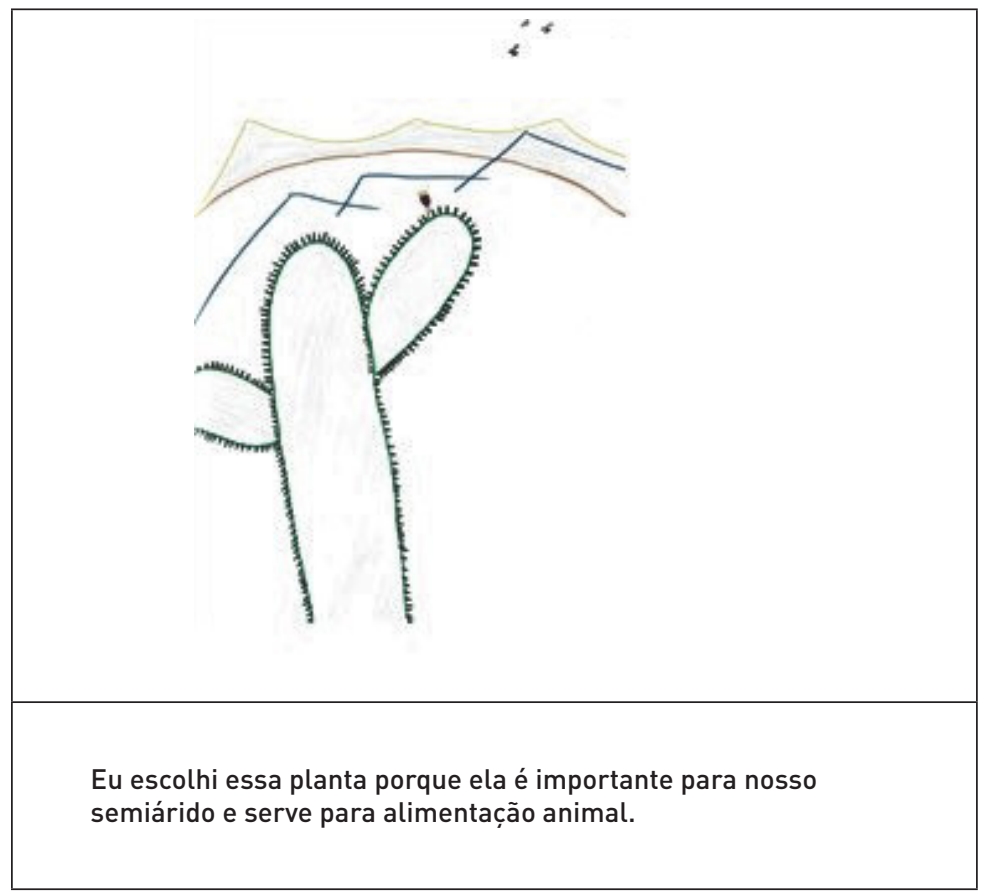

Fonte: Desenho e justificativa elaborados por estudante do $8^{\circ}$ ano da EFA.

A fala do estudante aponta a importância dessa espécie para a região, além da sua utilização para alimentar os animais. Essa importância pode estar relacionada às adaptações que essas espécies possuem como o reservatório de água em suas estruturas. Teixeira, Silva e Freixo (2018) argumentam que a proximidade dos estudantes da EFA com as espécies desse ambiente facilita o conhecimento acerca de suas adaptações para períodos de seca.

Segundo Baptista (2010), o ensino de ciências no Brasil ainda é baseado na substituição de saberes tradicionais pelo científico; no entanto, por apresentar forte relação com conhecimentos locais, o ensino de ciências tem a oportunidade de discutir diferentes interpretações da natureza, como meio de contribuir para um posicionamento crítico frente a sociedade, bem como valorização da sua cultura.

Para Andrade et al. (2014), a classificação e sistematização são processos naturais na formação de conceitos, e no que diz respeito ao conhecimento da biodiversidade e seus métodos de classificação, a contextualização com os conhecimentos prévios dos estudantes é indispensável, por apresentar diversas formas de interpretar e organizar os seres vivos. Diante dessa perspectiva apresentaremos a seguir as classificações intuitivas realizadas pelos estudantes da EFA.

\subsection{CLASSIFICAC̣ÃO ETNOTAXONÔMICA}

Sistemas de categorização foram criados pelo homem desde a antiguidade através de nomes como Aristóteles, Teofrastos e Lineu. Atualmente, com o 
advento da Teoria Evolutiva como meio para explicar a diversidade e a relação de parentesco entre as espécies, a Filogenia associada à Sistemática Taxonômica, busca compreender os processos responsáveis pela diversidade de espécies e seu sistema de classificação (ROMA; MOTOKANI, 2007). O Quadro 3 traz a relação das categorizações realizadas pela turma do $6^{\circ}$ ano.

Quadro 3. Categorias estabelecidas pelos alunos do $6^{\circ}$ ano da EFA

\begin{tabular}{|c|c|c|c|}
\hline GRUPO 1 & GRUPO 2 & GRUPO 3 & GRUPO 4 \\
\hline $\begin{array}{l}\text { Não comestíveis: Pau } \\
\text { de rato, Mandacaru, } \\
\text { São João, Sisal, } \\
\text { Orquídea, Maravilha, } \\
\text { Incó, Alecrim, } \\
\text { Gravatá, Xique-xique, } \\
\text { Arruda, Cebola } \\
\text { brava, Cabeça de } \\
\text { frade, Palma, Rosa, } \\
\text { Barriguda. }\end{array}$ & $\begin{array}{l}\text { Catingueira: } \\
\text { Mandacaru, Cabeça } \\
\text { de frade, Palma, } \\
\text { Incó, Xique-xique, } \\
\text { Sisal, Licuri. }\end{array}$ & $\begin{array}{l}\text { Rosas: Rosa, } \\
\text { Maravilha, } \\
\text { Orquídea, Pau de } \\
\text { rato, São João, } \\
\text { Pau Brasil, Cebola } \\
\text { brava, Umbu. }\end{array}$ & $\begin{array}{l}\text { Medicinais: Arruda, } \\
\text { Rosa, Maravilha, } \\
\text { São João, Capim } \\
\text { santo, Pau Brasil, } \\
\text { Alecrim, Maconha, } \\
\text { Erva cidreira, } \\
\text { Hortelã miúdo. }\end{array}$ \\
\hline \multirow{4}{*}{$\begin{array}{l}\text { Comestíveis: Erva } \\
\text { cidreira, Juá, } \\
\text { Hortelã miúdo, } \\
\text { Banana, Maconha, } \\
\text { Acerola, Capim } \\
\text { santo, Maçã, Umbu, } \\
\text { Licuri, Abacaxi, Cajá, } \\
\text { Aroeira. }\end{array}$} & $\begin{array}{l}\text { Ervas medicinais: } \\
\text { Capim santo, } \\
\text { Arruda, Hortelã } \\
\text { miúdo, Erva } \\
\text { cidreira, Maconha, } \\
\text { Cansanção. }\end{array}$ & $\begin{array}{l}\text { Caatinga: } \\
\text { Barriguda, Palma, } \\
\text { Mandacaru, Xique- } \\
\text { xique, Cabeça de } \\
\text { frade, Sisal. }\end{array}$ & $\begin{array}{l}\text { Frutos: Maçã, } \\
\text { Banana, Acerola. }\end{array}$ \\
\hline & $\begin{array}{l}\text { Flores: Rosa, } \\
\text { Maravilha, São } \\
\text { João, Pau Brasil, } \\
\text { Orquídea, Cerejeira. }\end{array}$ & $\begin{array}{l}\text { Ervas medicinais: } \\
\text { Maconha, Licuri, } \\
\text { Capim santo, Erva } \\
\text { cidreira, Arruda, } \\
\text { Cajá, Cansanção, } \\
\text { Hortelã miúdo. }\end{array}$ & $\begin{array}{l}\text { Caatinga: Sisal, } \\
\text { Barriguda, } \\
\text { Quixabeira, Cabeça } \\
\text { de frade, Licuri, } \\
\text { Mandacaru, Umbu, } \\
\text { Incó, Mandioca } \\
\text { Brava, Cebola brava, } \\
\text { Cansanção, Palma, } \\
\text { Juá, Gravatá. }\end{array}$ \\
\hline & $\begin{array}{l}\text { Legume: Cebola } \\
\text { brava, Mandioca } \\
\text { brava. }\end{array}$ & $\begin{array}{l}\text { Frutos: Mandioca } \\
\text { brava, Banana, } \\
\text { Acerola, Aroeira, } \\
\text { Maçã, Juá, Abacaxi, } \\
\text { Quixabeira. }\end{array}$ & \\
\hline & $\begin{array}{l}\text { Fruta: Maçã, } \\
\text { Banana, Umbu, } \\
\text { Cajá, Acerola, } \\
\text { Abacaxi, Juá. }\end{array}$ & & \\
\hline
\end{tabular}


Além dos critérios abordados pela Sistemática Filogenética, surgem novas formas de classificação, como as apontadas em trabalhos etnotaxonômicos, como forma de reconhecer a existência de outros modos de classificar os seres vivos (ANDRADE et al., 2014). Nesse trabalho, lançamos a proposta de fazer classificações intuitivas com os estudantes, com objetivo de conhecer os critérios e a forma de organização das plantas que estão disponíveis em seu cotidiano, tanto em casa como na escola. Os resultados obtidos pelas duas turmas diferem entre si, principalmente porque a turma do $6^{\circ}$ ano ainda não apresenta conhecimento acerca dos sistemas da classificação científica, dessa forma seus agrupamentos são totalmente intuitivos.

A análise das classificações realizadas pelo $6^{\circ}$ ano indicam a importância da etnobotânica no reconhecimento dos conhecimentos prévios de alunos de comunidades rurais, bem como na motivação durante a realização de atividades teórico-práticas que promovam o diálogo de saberes (OLIVEIRA et al., 2009; RODRIGUES; PASSADOR, 2010), além de discutir os conhecimentos que os estudantes apresentam sobre o uso dessas espécies.

Os critérios utilizados pelos grupos dessa turma foram primeiramente a forma de utilização das plantas pela comunidade. Andrade et al. (2014) encontraram resultados semelhantes em sua pesquisa, em que estudantes indígenas utilizaram formas diferentes para classificar os seres vivos, mas sempre usavam categorias que estivessem relacionadas ao uso nas suas aldeias. O grupo 1 apresentou duas categorias, divididas em plantas comestíveis e não-comestíveis, (Figura 5) demonstrando que os estudantes reconhecem visualmente as plantas que estão inseridas em seu cotidiano.

Figura 5. Cartaz confeccionado pelo grupo 1 do $6^{\circ}$ ano da EFA

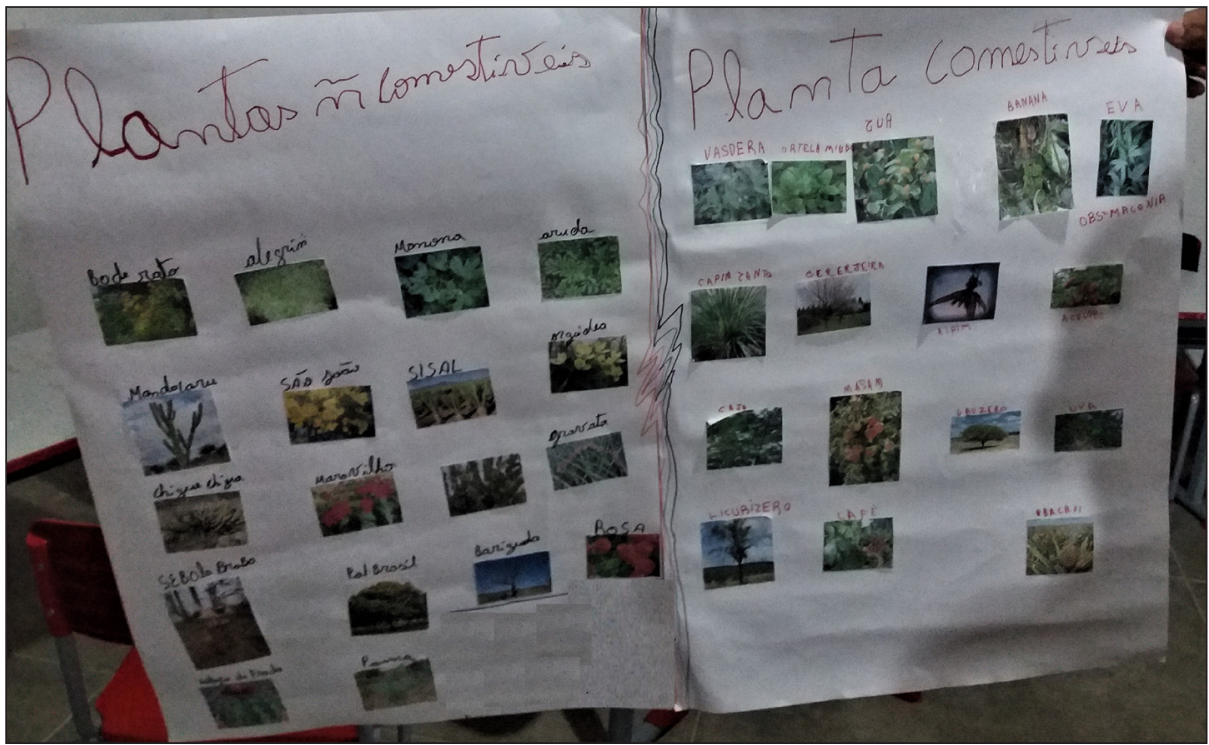

Fonte: Pesquisa de campo (2017)

As classificações realizadas pelos grupos da turma do $8^{\circ}$ ano estão dispostas no Quadro 4. Os cinco grupos do $8^{\circ}$ ano agruparam espécies como 
sendo de uso medicinal, justificando como utilizadas no tratamento de doenças ou que servem para fazer remédio caseiro.

Quadro 4. Categorias estabelecidas pelos alunos do $8^{\circ}$ ano da EFA

\begin{tabular}{|c|c|c|c|c|}
\hline GRUPO 1 & GRUPO 2 & GRUPO 3 & GRUPO 4 & GRUPO 5 \\
\hline $\begin{array}{l}\text { Frutíferas: } \\
\text { Abacaxi, } \\
\text { Banana, Cajá, } \\
\text { Licuri, Maçã, } \\
\text { Acerola, Juá, } \\
\text { Quixabeira, } \\
\text { Umbu }\end{array}$ & $\begin{array}{l}\text { Frutíferas: } \\
\text { Abacaxi, } \\
\text { Banana, Cajá, } \\
\text { Licuri, Maçãa, } \\
\text { Acerola, Juá, } \\
\text { Quixabeira, } \\
\text { Umbu, } \\
\text { Cerejeira }\end{array}$ & $\begin{array}{l}\text { Alimentação } \\
\text { animal: Palma, } \\
\text { Mandacaru, } \\
\text { Xique-Xique, } \\
\text { Cabeça de } \\
\text { Frade, Juá, } \\
\text { Incó, Gravatá/ } \\
\text { caroá, Sisal, } \\
\text { Mandioca } \\
\text { Brava, } \\
\text { Barriguda }\end{array}$ & $\begin{array}{l}\text { Frutíferas: } \\
\text { Abacaxi, } \\
\text { Banana, Cajá, } \\
\text { Licuri, Maçã, } \\
\text { Acerola, } \\
\text { Quixabeira, } \\
\text { Umbu, } \\
\text { Mandioca Brava }\end{array}$ & $\begin{array}{l}\text { Frutíferas: } \\
\text { Abacaxi, } \\
\text { Banana, Cajá, } \\
\text { Licuri, Maçã, } \\
\text { Acerola, Umbu }\end{array}$ \\
\hline $\begin{array}{l}\text { Alimentação } \\
\text { animal: } \\
\text { Mandacaru, } \\
\text { Cabeça de } \\
\text { Frade, Palma, } \\
\text { Sisal, Incó, } \\
\text { Xique-Xique, } \\
\text { Caroá/Gravatá, } \\
\text { Mandioca Brava }\end{array}$ & $\begin{array}{l}\text { Floríferas: } \\
\text { São João, Pau } \\
\text { Brasil, Rosa, } \\
\text { Orquídea, } \\
\text { Pau de Rato, } \\
\text { Maravilha, } \\
\text { Cansanção, } \\
\text { Erva Cidreira }\end{array}$ & $\begin{array}{l}\text { Floríferas: } \\
\text { São João, Pau } \\
\text { Brasil, Rosa, } \\
\text { Orquídea, } \\
\text { Pau de Rato, } \\
\text { Maravilha, } \\
\text { Cebola Brava, }\end{array}$ & $\begin{array}{l}\text { Medicinais: } \\
\text { Capim Santo, } \\
\text { Arruda, } \\
\text { Aroeira, } \\
\text { Maconha, } \\
\text { Cebola Brava, } \\
\text { Alecrim, } \\
\text { Hortelã Miúdo, } \\
\text { Erva Cidreira }\end{array}$ & $\begin{array}{l}\text { Medicinais: } \\
\text { Capim Santo, } \\
\text { Arruda, Aroeira, } \\
\text { Maconha, } \\
\text { Alecrim, } \\
\text { Hortelã Miúdo, } \\
\text { Erva Cidreira, } \\
\text { Pau de Rato }\end{array}$ \\
\hline $\begin{array}{l}\text { Floríferas: } \\
\text { São João, Pau } \\
\text { Brasil, Rosa, } \\
\text { Orquídea, } \\
\text { Cebola Brava, } \\
\text { Maravilha, } \\
\text { Cansanção }\end{array}$ & $\begin{array}{l}\text { Medicinais: } \\
\text { Capim Santo, } \\
\text { Arruda, } \\
\text { Aroeira, } \\
\text { Maconha }\end{array}$ & $\begin{array}{l}\text { Frutíferas: } \\
\text { Abacaxi, } \\
\text { Banana, Cajá, } \\
\text { Licuri, Maçã, } \\
\text { Acerola, Umbu, } \\
\text { Cerejeira, }\end{array}$ & $\begin{array}{l}\text { Flores: Rosa, } \\
\text { Maravilha, } \\
\text { Orquídea, } \\
\text { Cerejeira, } \\
\text { Cansanção, Pau } \\
\text { de Rato, Pau } \\
\text { Brasil, São João }\end{array}$ & $\begin{array}{l}\text { Alimentação } \\
\text { animal: } \\
\text { Mandioca } \\
\text { Brava, Gravatá/ } \\
\text { caroá, Sisal, } \\
\text { Juá, Incó, } \\
\text { Quixabeira }\end{array}$ \\
\hline \multirow[t]{3}{*}{$\begin{array}{l}\text { Medicinais: } \\
\text { Capim Santo, } \\
\text { Erva Cidreira, } \\
\text { Barriguda, } \\
\text { Arruda, } \\
\text { Aroeira, Pau de } \\
\text { Rato, }\end{array}$} & $\begin{array}{l}\text { Suculentas: } \\
\text { Sisal, Palma, } \\
\text { Xique-Xique, } \\
\text { Mandacaru, } \\
\text { Cabeça de } \\
\text { Frade }\end{array}$ & $\begin{array}{l}\text { Medicinais: } \\
\text { Capim Santo, } \\
\text { Erva Cidreira, } \\
\text { Arruda, } \\
\text { Aroeira, Hortelã } \\
\text { Miúdo }\end{array}$ & $\begin{array}{l}\text { Com espinhos: } \\
\text { Mandacaru, } \\
\text { Palma, Cabeça } \\
\text { de Frade, } \\
\text { Xique-Xique, } \\
\text { Sisal, Caroá }\end{array}$ & $\begin{array}{l}\text { Floríferas: } \\
\text { Cebola Brava, } \\
\text { São João, } \\
\text { Barriguda, } \\
\text { Maravilha, } \\
\text { Cansanção, } \\
\text { Rosa, Orquídea, } \\
\text { Cerejeira, Pau } \\
\text { Brasil }\end{array}$ \\
\hline & $\begin{array}{l}\text { Tubérculos: } \\
\text { Mandioca } \\
\text { Brava, Cebola } \\
\text { Brava }\end{array}$ & & & $\begin{array}{l}\text { Cactácea: } \\
\text { Palma, } \\
\text { Mandacaru, } \\
\text { Xique-Xique, } \\
\text { Cabeça de } \\
\text { Frade }\end{array}$ \\
\hline & $\begin{array}{l}\text { Independentes: } \\
\text { Incó, Gravatá, } \\
\text { Alecrim }\end{array}$ & & & \\
\hline
\end{tabular}


Todos os grupos utilizaram a categoria frutíferas para aquelas espécies que davam frutos para o próprio consumo ou para serem comercializados, evidenciando mais uma vez aspectos abordados no Projeto Político Pedagógico da escola (EFA VALENTE, 2015), que trabalha a participação desses jovens em atividades práticas na família, aplicando novos conhecimentos, e percebendo a relação entre trabalho e produção, além da contribuição familiar na aquisição de tal conhecimento (LIMA; FREIXO, 2012).

Outro resultado interessante foi apresentado pelo grupo 2, que apresentou a categoria de plantas suculentas e tubérculos, observando características morfofisiológicas das plantas que compõem esses grupos, explícito na fala "Suculentas são plantas que armazenam água", "tubérculos são as plantas que dão batatas", indicando provavelmente que esses estudantes recorreram a conhecimentos abordados na escola anteriormente. Além da percepção morfológica, os grupos 2 e 5 compreenderam que mesmo fazendo parte de um determinado grupo, as espécies podem ser inseridas em outras categorias, o que ficou explícito na fala de um dos estudantes: "Apesar de que as floríferas poderiam se encaixar nas frutíferas pq [sic] algumas floríferas também dão fruto."

O grupo 2 apresentou ainda a categoria denominada independentes, e justificaram tal escolha por: "não reconhecemos essas espécies e não sabíamos em qual grupo colocá-las". Esse resultado está de acordo com Andrade et al. (2014), quando afirmam que através do conhecimento a respeito dos seres é possível escolher qual a melhor forma de interpretar e organizar esses seres para que se tenha uma melhor compreensão acerca dos seres vivos. O grupo 5 relacionou as plantas encontradas na região como sendo as Cactáceas, caracterizadas pelo grupo como representantes do bioma Caatinga e que têm importância para as comunidades, pois utilizam essas plantas como por exemplo o sisal como meio de sustento. $\mathrm{O}$ sentimento de pertencer à caatinga por essa comunidade rural, já foi retratado em outros trabalhos no mesmo contexto (TEIXEIRA; SILVA; FREIXO, 2018; LIMA; FREIXO, 2012) e que são reafirmados com nossos resultados, valorizando mais uma vez a abordagem do PE e sua importância para as famílias que estão envolvidas com a EFA.

Observando as categorias estabelecidas pelas duas turmas, é notória a importância dos conhecimentos prévios dos estudantes sobre a biodiversidade para o ensino de sistemas de classificação biológica. Observamos também que a maioria das categorias estabelecidas eram baseadas naquelas exercidas pelos antigos herbalistas, que reuniam as espécies em grupos de acordo com seu uso prático (COSTA, 2012) como as plantas medicinais, as utilizadas na alimentação seja humana ou animal, e ornamentação. No entanto, algumas categorias se aproximaram mais com a classificação Histórica-Evolutiva, apresentando critérios como características similares entre as espécies, como o grupo de plantas com espinho, suculentas e tubérculos. Costa e Waizbort (2013) encontraram resultados semelhantes em sua pesquisa sobre as concepções dos estudantes sobre a classificação biológica, e enfatizaram a importância de pensar a forma e o momento de desenvolver atividades que levem os estudantes a se questionarem sobre os mecanismos evolutivos. 
Lima e Freixo (2012) apontam para a importância de contextualização pedagógica e o diálogo de saberes em sala de aula como ferramenta no processo de ensino e aprendizagem, bem como a valorização das culturas tradicionais. Andrade et al. (2014, p. 6402) afirmam que "nos sistemas de classificação biológica ocidental e classificações baseadas nos conhecimentos populares locais, há uma riqueza de informações que passam a estar disponíveis para uso diante das diferentes situações". Esse diálogo de saberes será abordado no tópico seguinte.

\subsection{DIÁLOGO DE SABERES}

$\mathrm{Na}$ última etapa da pesquisa, buscamos estabelecer um momento para a promoção do diálogo entre os saberes científicos e os saberes populares. Apresentamos um cartaz semelhante ao que os participantes da pesquisa realizaram durante a oficina, contendo a organização das plantas separadas em grupos mediante critérios taxonômicos (Figura 6). De acordo com esses critérios, reunimos as espécies em seis clados: Asparagales, Asterideales, Comelinideas, Cariophillales, Malvidiales, e Fabidiales, segundo o site Phylogenetic Tree Generator (LETUNIC; BORK, 2006), que gerou uma árvore filogenética apresentada na Figura 7.

No momento da apresentação para as turmas, foi exposto um pouco da história da taxonomia, como eram realizadas as primeiras classificações e explicados termos como cladrogamas, sinapormofias e plesiomorfia. Também destacamos a importância de ter um sistema universal de classificação, para que dessa forma não haja equívocos nem distorções, quando alguém se referir a determinada espécie. Logo na primeira parte do trabalho, uma aluna escolheu a planta pau de rato (Poincianella pyramidalis (Tul.) L. P. Queiroz), que é bastante utilizada para o tratamento de diarreia na região, no entanto em outras comunidades essa mesma espécie é conhecida como catinga de porco e/ou catingueira, para o mesmo fim medicinal. Com isso, exemplificamos para a turma a importância em saber exatamente a que espécie nos referimos, por exemplo, ao se tratar de plantas medicinais para que não aconteça uma automedicação equivocada. 
Ensino de Botânica e classificação biológica em uma Escola família agrícola: diálogo de saberes no campo

Figura 6. Cartaz ilustrando a classificação das plantas trabalhadas

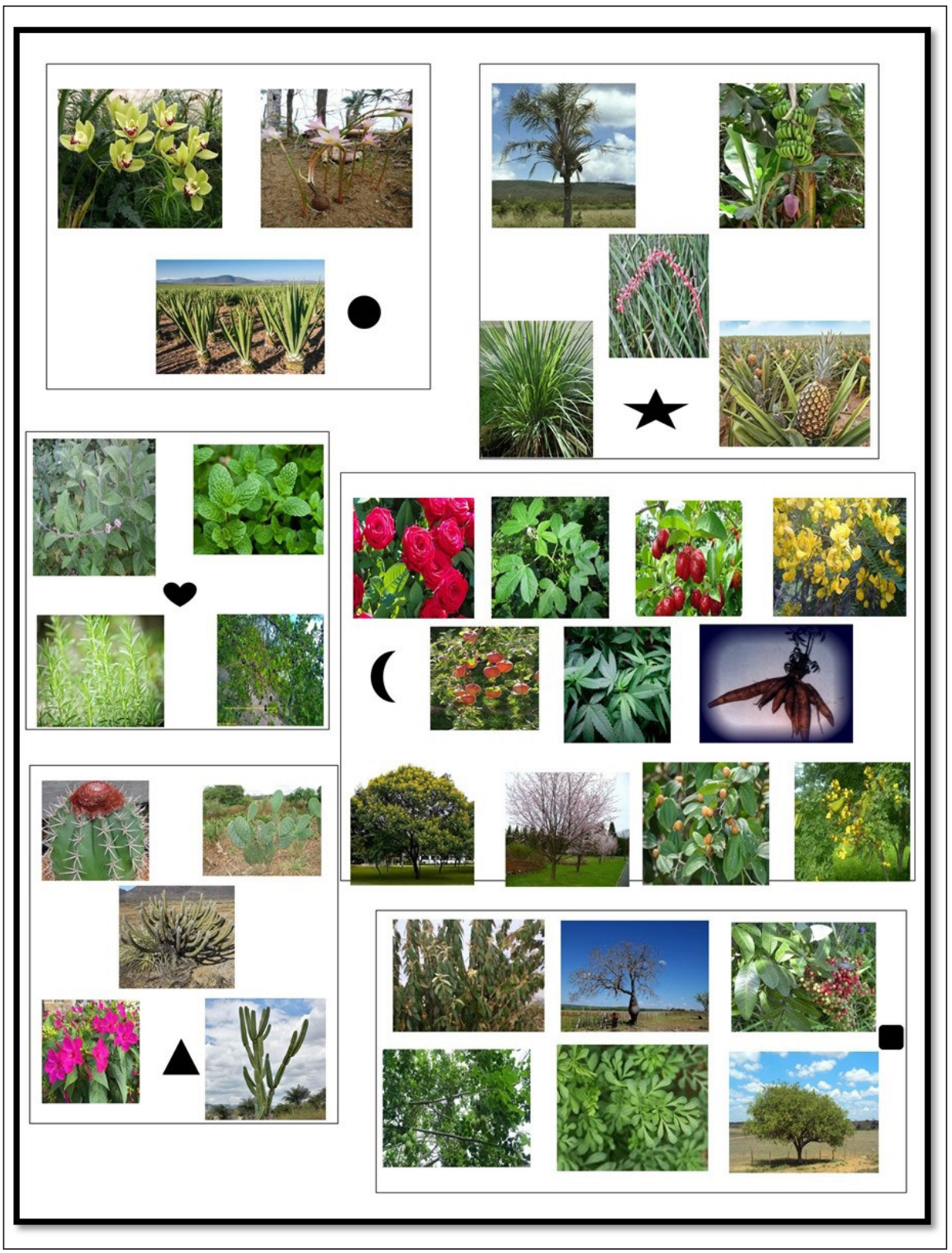

Fonte: Pesquisa de campo (2017). 
Figura 7. Cartaz ilustrando o cladograma das plantas

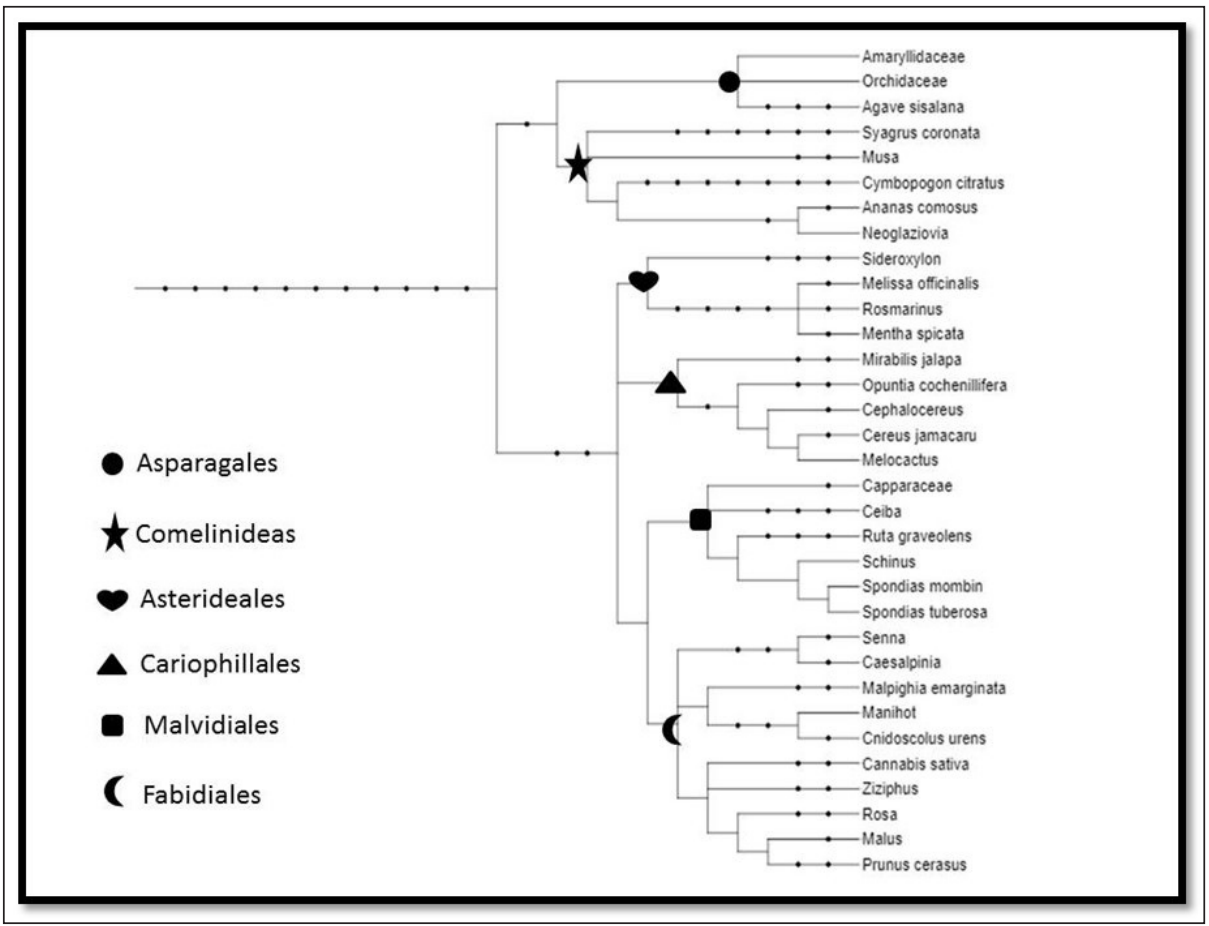

Fonte: Pesquisa de campo (2017).

Baptista (2007) afirma que o ensino de ciências pautado na supervalorização dos saberes científicos em relação aos saberes tradicionais, pode direcionar os estudantes a conflitos entre essas duas explicações. Dessa forma, nossa pesquisa buscou promover o diálogo entre esses saberes para que os estudantes pudessem agregar informações ao conhecimento que eles já possuem. Essa perspectiva de ensino pautado na demarcação de saberes, segundo Baptista (2010), permite aos estudantes compreenderem que existem outras formas de explicação da natureza, além daquelas que fazem parte do seu cotidiano.

Ao analisar o cartaz com a classificação científica, os estudantes se entusiasmaram com os grupos organizados e chamaram atenção para o clado das Asparagales, composto pelo sisal, cebola brava e orquídea. Para eles, o que chama mais atenção são os critérios morfológicos e funcionais, por isso não imaginavam que a orquídea, utilizada na ornamentação, e classificada por eles como o grupo das flores/rosas pudesse ser parente próxima do sisal, classificado como planta da caatinga, ou utilizado na alimentação animal. O clado das Cariophillales também teve essa observação, já que as cactáceas apresentam estruturas e hábito característico, como a retenção de água e presença de espinhos, além de serem utilizadas basicamente na alimentação de animais, enquanto a maravilha (Mirabilis jalapa L.) foi classificada por eles como planta medicinal e no grupo das flores.

Discutimos que não existe uma forma errada de classificação, o que ocorre são abordagens e critérios diferentes utilizados na categorização da biodiversidade. 
Andrade et al. (2014) defendem que as diversas formas de interpretar e organizar os seres vivos requerem conhecimentos a respeito desses seres para então, possibilitar a escolha de qualquer método de classificação. Os participantes dessa pesquisa reconheceram a importância de ter acesso a conhecimentos diferentes (científico e tradicional) para usar em ambientes apropriados, reconhecendo a demarcação de saberes e corroborando com Baptista (2007), quando afirma em seu trabalho que os estudantes, ao terem acesso a diferentes modos de conhecimento, podem escolher em qual contexto utilizá-lo.

No momento seguinte, entregamos um livreto (SOUSA; SILVA, 2017), que reúne informações sobre as espécies abordadas durante a oficina, os desenhos realizados pelos estudantes, informações sobre classificação filogenética e exemplo das classificações intuitivas realizadas por eles.

A primeira reação dos estudantes foi eufórica, ao ver seus desenhos representados no trabalho, eles compartilhavam com os colegas de classe e apreciaram as informações e curiosidades que eram apresentadas sobre cada espécie. A confecção e entrega do livreto foi uma forma de devolutiva para a escola, de forma que pudessem guardar para consultas posteriores.

Após o contato com o livreto, reunimos as duas turmas no auditório da escola para fazer uma socialização do que tinha significado o trabalho, visto que uma turma trabalhou com plantas e a outra com animais em cada sessão. De forma geral, os estudantes elogiaram a oficina e disseram ter gostado de participar, pois perceberam que existem várias possibilidades de organizar os seres vivos e aprenderam informações novas sobre as espécies que eles tinham contato.

\section{CONSIDERACְÕES FINAIS}

Levando-se em consideração a relação entre conhecimentos tradicionais, plantas da caatinga, educação do campo, e o ensino de ciências, trabalhar com os alunos do sexto e oitavo anos do ensino fundamental temas como biodiversidade e classificação biológica, envolvendo os conhecimentos prévios e vivências com a comunidade rural se faz de grande importância, tanto para abordar o conhecimento científico como para criar laços com a comunidade em que eles se encontram.

A partir da investigação a respeito dos conhecimentos prévios dos estudantes sobre as plantas, observamos a proximidade dos participantes dessa pesquisa com as mesmas, pois percebemos em suas falas a importância das espécies no cotidiano desses indivíduos e dos coletivos em que vivem. Além da relação direta com a sobrevivência no meio rural, eles demonstraram preocupação em entender e preservar a biodiversidade que está a sua volta.

Destacamos que a turma do $6^{\circ}$ ano carrega muitas informações aprendidas em suas comunidades, enfatizando o uso medicinal das plantas. Já o $8^{\circ}$ ano apresenta informações a respeito do convívio na região, da utilização das plantas como meio de sobrevivência para a família, bem como das plantas utilizadas na alimentação de animais.

Tendo em vista os aspectos observados a respeito da relação dos estudantes da EFA com as plantas, buscamos compreender o processo de construção do diálogo entre conhecimentos prévios e os sistemas de classificação elaborados pelos estudantes, com os sistemas de classificação produzidos pela ciência. Assim, 
destacamos que ambas as turmas participantes utilizam a morfologia e a utilidade das plantas para classificá-las.

Os resultados obtidos nesse trabalho mostram a significância das oficinas de ciências que abordam aspectos relacionados à classificação biológica, como um instrumento facilitador da aprendizagem e na valorização dos saberes da comunidade, proporcionando assim, o diálogo entre conhecimento tradicional e científico na EFA.

Percebemos que, embora existam muitas pesquisas buscando estratégias para facilitar o ensino de botânica, é necessário ampliar o campo de trabalho nas comunidades tradicionais, pois existem muitas informações que são desconhecidas pela ciência, e que são amplamente vivenciadas nesses locais, trazendo uma riqueza de detalhes e informações pertinentes. Assim, os estudos etnobotânicos possibilitam a compreensão das relações estabelecidas com as espécies vegetais, visando a preservação da biodiversidade e dos conhecimentos adquiridos através da relação do ser humano com o meio em que está inserido.

Portanto, a proposta metodológica desenvolvida nessa pesquisa nos mostra que apesar das dificuldades encontradas em promover um ensino de ciências que abarque a multiculturalidade da sala de aula, é possível pensar em estratégias que se aproximem do cotidiano dos alunos, possibilitando um ensino contextualizado de ciências, ampliando o diálogo de saberes e o fortalecimento do sentimento de pertencimento entre os estudantes e sua comunidade.

\section{Apoio Financeiro: PROEX/MEC SESu 2013.}

\section{REFERÊNCIAS}

ANDRADE, R. C. et al. Classificação biológica: uma experiência pedagógica junto a estudantes de um curso de formação intercultural de educadores indígenas. Revista SBEnBIO, n. 7, p. 6392-6402, 2014. Disponível em: https://docplayer.com.br/28672877-Classificacao-biologica-uma-experienciapedagogica-junto-a-estudantes-de-um-curso-de-formacao-intercultural-de-educadores-indigenas. html. Acesso em: 30. abr. 2020.

ARAÚJO, C. S.; SOBRINHO, J. F. O bioma caatinga no entendimento dos alunos da rede pública de ensino da cidade de Sobral, Ceará. Revista Homem, Espaço e Tempo, v. 3, n. 1, 2009. Disponível em: https://docplayer.com.br/11104118-O-bioma-caatinga-no-entendimento-dos-alunos-da-redepublica-de-ensino-da-cidade-de-sobral-ceara-1.html. Acesso em: 30. abr. 2020.

BAPTISTA, G. C. S. Importância da demarcação de saberes no ensino de ciências para sociedades tradicionais. Ciência \& Educação, v. 16, n. 3, p. 679-694, 2010. Disponível em: http:/ /www.scielo. br/pdf/ciedu/v16n3/v16n3a12.pdf. Acesso em: 30. abr. 2020.

BAPTISTA, G. C. S. A contribuição da etnobiologia para o ensino e a aprendizagem de ciências: estudo de caso em uma escola pública do estado da Bahia. 2007. 250 p. Dissertação (Mestrado em Ensino, Filosofia e História das Ciências) - Universidade Federal da Bahia e Universidade Estadual de Feira de Santana. Salvador. Disponível em: https://repositorio.ufba.br/ri/bitstream/ri/15805/1/ Geilsa\%20Costa\%20Santos\%20Baptista.pdf. Acesso em: 30. abr. 2020. 
BARDIN, L. Análise de conteúdo. São Paulo: Edições 70, 229 p. , 2004.

BITENCOURT, R. B.; MARQUES, J.; MOURA, G. J. B. de. O imaginário sobre a Caatinga representada nos desenhos infantis de estudantes do Nordeste do Brasil. Revista Brasileira de Educação Ambiental (RevBEA), v. 9, n. 2, p. 254-269, 2014. Disponível em: http://revbea. emnuvens.com.br/revbea/article/download/4011/2898. Acesso em: 30. abr. 2020.

COSTA, L. de O.; WAIZBORT, R. F. Concepções de alunos do ensino médio sobre o tema Classificação Biológica. Investigações em Ensino de ciências, v. 18, n. 3, p. 667-680, 2013. Disponível em: https://www.if.ufrgs.br/cref/ojs/index.php/ienci/article/view/119/83. Acesso em: 30. abr. 2020.

COSTA, L. de O. A classificação biológica nas salas de aula: modelo para um jogo didático. 2012. Dissertação (Pós-graduação em Ensino de Biociências e saúde) Instituto Fio Cruz, Rio de Janeiro, 2012. Disponível em: https://www.arca.fiocruz.br/bitstream/icict/6410/1/leandro_costa_ mp_2012.pdf. Acesso em: 30. abr. 2020.

EFA VALENTE. Projeto Político Pedagógico. Valente: EFA VALENTE, 2015.

FERREIRA, F. S. et al. A zoologia e a botânica do ensino médio sob uma perspectiva evolutiva: uma alternativa de ensino para o estudo da biodiversidade. Cadernos de Cultura e Ciência, v. 2, n. 1, p. 58-66, 2008. Disponível em: http://periodicos.urca.br/ojs/index.php/cadernos/article/ download/19/19-59-2-PB. Acesso em: 30. abr. 2020.

LETUNIC, I.; BORK, P. Interactive Tree Of Life (iTOL): an online tool for phylogenetic tree display and annotation. Bioinformatics, v. 23, n. 1, p. 127-128, 2006. Disponível em: https:/ /academic.oup. com/bioinformatics/article/23/1/127/188940. Acesso em: 30. abr. 2020 (Ferramenta disponível em: https://phylot.biobyte.de/. Acesso em: 30. abr. 2020).

LIMA, L. da A.; FREIXO, A. A. Saberes e Sabores do Campo: Relações entre Conhecimentos Científicos e Tradicionais Numa Escola Família Agrícola do Sertão da Bahia. Revista Metáfora Educacional, n. 13, p. 21-35, 2012. Disponível em: https://dialnet.unirioja.es/servlet/ articulo?codigo $=4153132$. Disponível em: 30. abr. 2020.

OLIVEIRA, F. C. de, et. al. Avanços nas pesquisas etnobotânicas no Brasil. Acta bot. bras, v. 23, n. 2, p. 590-605, 2009. Disponível em: http://www.scielo.br/pdf/abb/v23n2/v23n2a31. Acesso em: 30. abr. 2020.

OLIVEIRA, J. F. C.; FREIXO, A. A. Contribuições de um herbário escolar para o ensino de ciências no contexto da Educação do Campo. Ciência \& Desenvolvimento-Revista Eletrônica da FAINOR, v. 12, n. 2, 2019. Disponível em: http://srv02.fainor.com.br/revista/index.php/ memorias/article/view/935. Acesso em: 30. abr. 2020.

RODRIGUES, M. de A.; PASSADOR, R. Jr. Etnoconhecimento: uma possibilidade de diálogo para o ensino. In: FÓRUM DE EDUCAÇÃO E DIVERSIDADE, 4., 2010, Tangará da Serra. Anais... Tangará da Serra: UNEMAT, 2010. Disponível em: http://need.unemat.br/4_forum/artigos/ mariana.pdf. Acesso em: 30. abr. 2020.

ROMA, V. N.; MOTOKANE, M. T. Classificação biológica nos livros didáticos de Biologia do ensino Médio. In: ENCONTRO NACIONAL DE PESQUISA EM ENSINO DE CIÊNCIAS, 6. Florianópolis, 2007. Anais... Florianópolis: ABRAPEC, 2007. Disponível em: http://www.nutes. ufrj.br/abrapec/vienpec/CR2/p878.pdf. Acesso em: 30. abr. 2020. 
SHAW, C. A. ITIS (The Integrated Taxonomic Information System). 2004. Disponível em: https://www.itis.gov/. Acesso em: 30. abr. 2020.

SOUSA, D. K. C. de; FREIXO, A. A. Sistemas de classificação intuitiva como possibilidade para o ensino de diversidade animal no contexto da educação do campo. Revista Brasileira De Pesquisa Em Educação Em Ciências, v. 20, p. 193-220. Disponível em: https://periodicos.ufmg.br/index. $\mathrm{php} / \mathrm{rbpec} /$ article/view/16066. Acesso em: 30. abr. 2020.

SOUSA, D. K. C. de; SILVA, I. T. da. Bichos e plantas que conhecemos! Trabalhando biodiversidade e classificação. 2017. Disponível em: https://www.researchgate.net/ publication/333224444_Bichos_e_plantas_que_conhecemos. Acesso em: 30. abr. 2020.

SILVA, L. H. da. Educação do Campo e Pedagogia da Alternância: a experiência brasileira. Sísifo. Revista de Ciências da Educação, v. 5, p. 105-112, 2008.

TEIXEIRA, M. L. da S.; SILVA, J. P. dos S.; FREIXO, A. A. A Caatinga em imagens: representações de estudantes de dois contextos socioculturais da Bahia. Rev. educ. PUC-Camp., v. 23, n. 3, p. 455470, 2018. Disponível em: http://periodicos.puc-campinas.edu.br/seer/index.php/reveducacao/ article/view/3950. Acesso em: 30. abr. 2020.

TEIXEIRA, A. M. F.; FREIXO, A. A. Educação do campo e memória de velhos: navegando entre o passado e o presente. Revista Contrapontos, v. 11, n. 1, p. 14-23, 2011. Disponível em: http:// www6.univali.br/seer/index.php/rc/article/view/2261. Acesso em: 30. abr. 2019.

THE Plant List. Versão 1.1. 2013. Disponível em: http://www.theplantlist.org/. Acesso em: 30. abr. 2020.

TRIPP, D. Pesquisa-ação: uma introdução metodológica. Educação e Pesquisa, v. 31, n. 3, p. 443-466, 2005. Disponível em: http://www.scielo.br/pdf/ep/v31n3/a09v31n3.pdf. Acesso em: 30. abr. 2020.

VERGUTZ, C. B.; CAVALCANTE, L. O. H. As aprendizagens na Pedagogia da Alternância e na Educação do Campo. Reflexão e Ação, v. 22, n. 2, p. 371-390, 2014. Disponível em: https://online. unisc.br/seer/index.php/reflex/article/view/5057/3697. Acesso em: 30. abr. 2020.

URSI, S., et al. Ensino de Botânica: conhecimento e encantamento na educação científica. Estudos Avançados, v. 32, n. 94, p. 7-24, 2018. Acesso em: 26. Set. 2019. Disponível em: http:/ /www.scielo. br/pdf/ea/v32n94/0103-4014-ea-32-94-00007.pdf. Acesso em: 30. abr. 2020.

Submetido em 07/01/2020

Aprovado em 20/07/2020

\section{Contato:}

Alessandra Alexandre Freixo

Universidade Estadual de Feira de Santana (UEFS)

Departamento de Educação

Avenida Transnordestina, s/n - Novo Horizonte

CEP. 44.036-900 - Feira de Santana, BA - Brasil 